\title{
CRM to Support International Relationships in a Global Society
}

\author{
Milena Janakova ${ }^{1, *}$ \\ ${ }^{1}$ Silesian University in Opava, School of Business Administration in Karvina, Department of \\ Informatics and Mathematics, Univerzitni nam. 1934/3, 73340 Karvina, Czech Republic
}

\begin{abstract}
.
Research background: Competitive pressure and high customer expectations lead to the use of new innovations for communication with customers. In many cases, this communication is based on CRM systems. CRM systems have great capabilities, but the current problem is evident in the difficulty of choosing the optimal CRM for small businesses due to doubts about unexpected needs (such as human sources, necessary hardware and software, finances and time).

Purpose of the article: The aim of this paper is to support optimal customer contact through better CRM (Customer Relationship Management) implementation in a global society. The purpose of this article is to determine the necessary metrics (not just tough financial issues) to know the preferences for CRM with their weights. This information shows the possibilities of choosing the optimal CRM systems for business support to be improved in terms of automation and social media integration.

Methods: The method solution is based on a review of the literature, specification of suitable metrics such as automation, cloud, free access, mobile access, segmentation, social media integration, and templates. The following data collection is the basis for a discussion on the possibilities of CRM implementation.

Findings \& Value added: The findings are based on the results of multidimensional decision making, which uses a comparison of selected criteria (such as the Fuller's triangle). The value added is visible in the recommendation on how to choose a CRM system for small business to share the necessary information between marketers and customers through social networks to build a brand.
\end{abstract}

Keywords: CRM; globalization; information technology; international relationships; knowledge

JEL Classification: $D 8 ; C 8 ; M 3$

\footnotetext{
*Corresponding author:mija@,opf.slu.cz
} 


\section{Introduction}

People and the relationships between them have been formed naturally for each other since the beginning of humanity. Information technology (IT) now has amazing capabilities to connect people on a global scale. Modern society is very dynamic and information is shared in many forms though websites, blogs, discussing groups or specialized educational portals. Perhaps all fields use information technology to support the implemented activities. The same situation is in the area of contacts with customers. It is CRM (Customer Relationship Management). For enterprises, CRM creates a basis for communication with the customer, offers marketing presentations, stores the necessary data for further processing, and, of course, big data analytics $[1,2]$.

Customers' preferences and understanding their needed with trend estimates are interesting. The reasons are pragmatic, as the aim is to prevent unexpected crises and to have time to prepare the necessary measures. Sustainable development is also coming to the fore. To analyze the optimal contact with the customer with the support of CRM in a global society, appropriate CRM systems must match specified metrics according to the preferences of business to support international relationships in a global society. For optimal solution, the article is divided into several chapters. There is a literature review search on the topic of international relationships and CRM (Chapter 1 and 2). The literature review focuses on articles in scientific journals indexed in the Web of Science (special interest is in journals with Q1 and Q2), conference proceedings, and book series. These chapters provide a good overview of current topics and issues that need to address. The following chapter is devoted to the specification of the existing problem, the solution of the selected method, and the achieved results (Chapter 3). There are also room for discussion, conclusions and references. These references come are from 1996, but many of them from 2020.

\subsection{International Relationships}

Understanding life in the local place where people live is a difficult matter. There are many aspects that affect the implemented activities. Understanding international relationships is more difficult because it involves the world and different preferences, cultures, possibilities, and traditions. In modern society, people are consumers in a global perspective and eshopping or websites create an environment for buying the goods they need, regardless of the location of event. Customers are smart and have a very good overview of the current situation. This is pragmatic, as a Google search offers many links to resources to learn about different opinions and prices. Many businesses need to know the common behaviour of customers and how to influence their decisions through memes. Artificial intelligence has interesting results in managing cooperating consumer networks [3, 4].

Information technology are increasingly important for working with the customer in the implemented activities. There are visible changes in implemented IT, such as the dominant trend of globalization [5]. International relationships create an area that has great potential to influence the positive growth of the volume of customers regardless of age [6]. There is a special interest in long-term contacts with customers and their loyalty to support repeat purchases. A typical example of integrating IT into international relations with benefits is visible when using CRM in tourism. CRM systems offer a default menu for storing the necessary data about customers and their behaviour, preferences, orders, and invoices. Other options are the integration of automated processes and artificial intelligence; but these implementations are more limited to opulent solutions. The visible result is reflected in a better competitive advantage, which is irreplaceable in dynamic global markets.

The importance of CRM demonstrates the impact of CRM technology on sales process behaviour [7]. CRM systems have been evaluated by building relationships and managing 
opportunities in the US, Europe, and Asia. CRM software is now the largest software market in the world, and growth is not slowing down. From actual figures, it is estimated that CRM will reach approximately $\$ 80$ billion by 2025 [8]. Businesses use CRM systems regardless of their size. It is estimated that approximately $91 \%$ of enterprises with more than 11 employees use CRM. The key features of CRM systems are mobile and cloud systems, realtime access to customer data, and CRM technology to implement customer contact with a more personalized experience.

Of particular interest are such CRM solutions to support customer service, marketing automation, sales force automation, knowledge management, channel management, and call centres. These processes are also influenced by international relations. It requires a new approach to new product development [9] and the necessary processes to support the customer life-cycle [10]. The implementation of CRM processes must help to support the shortest development time, the highest quality, and the lowest cost. Zoom again focuses on a customer-centred approach and international customer relations. In these relationships, human, organizational and technological resources have an impact on implemented CRM systems and processes in all phases of the customer's life-cycle. For these tasks, it is necessary to understand the international relationships in a global society and share the necessary knowledge about CRM systems.

\subsection{Customer Relationship Management (CRM)}

CRM systems are implemented to support customer relationships and their management. The default CRM specification states that CRM integrates the necessary strategies, techniques, tools, and technologies for the effective and quality development of customer relationships to implement key CRM requirements [11]. The success of CRM affects the multidimensional links between the adopted strategy and the organizational culture with an impact on the effect of customer orientation [12]. Social networks are also an important part of CRM. There is social CRM and specialized models for the interrelationships between its abilities are analyzed [13]. The specialized role is implemented in technologies, customer initiatives, information from social processes to growing profit from customer relationships.

To develop international relationships, CRM uses social networks to build general brand awareness through information sharing, and to attract and maintain customers. In these relationships, marketers and sales people very often care about social mission to stay in touch with customers and potential customers [14]. In many cases, it is their personal relationships. The pragmatic evaluation of marketers and sales people is based on financial metrics. Financial matters (profit, costs, revenues, return on investment) are very often influenced by soft metrics such as the number of opportunities. For opportunities, it is essential to decide on the opportunities leading to purchasing, or it is better to cancel such communication [15].

In order to have an optimal sales estimate based on reality, it needs comprehensive tools to support the required performance. The best solution for marketers and sales people is to get a group of selected customers for further communication with a high probability of concluding a purchase that the estimated numbers are met. And again, artificial intelligence has an important place here. It is about influencing customer acquisition, development and retention [16]. For better results, customer and product-oriented service analysis is needed [17]. Interest is in the original segmentation of customers and product-oriented services in order to analyze the timeliness, frequency and financial value. The model of customer behaviour [18] with forecasting and other classification methods [19] are also important. This information is aimed at promoting competitive advantage in international relationships. Along the way, communication with customers is based on sensitive care, which increases customer loyalty and purchases. 
Knowledge and good orientation in the topic bring the estimated success of IT implementation. Similarly, it is important for CRM systems to know about current trends and learn from mistakes [20] in order to make better use of marketing and knowledge management. Global society is putting pressure on knowledge to improve customer relationship and innovation; the reason is to be highly competitive against strong competition and meet customer requirements. Many businesses rely on CRM systems that have the benefits of supporting long-term customer relationships. The situation is difficult for small business. They have limited resources and there is a difficult human resources situation where there is a shortage of IT experts. These businessmen have doubts about the use of modern information technologies with regard to digital transformation and sustainability [21]. The existing controversy is visible is the IT capabilities and unnecessary doubts of small business about IT innovation. The reason is that IT has great potential to help solve the current problem in such a situation.

\section{Methodology and Data}

Based on the above literature review, it is clear that CRM systems play an important role in enterprises at local level and are also needed at the global level to support international relationships. The existing controversy is visible at the implementation level. This is a very sensitive issue for small business, as they lack IT specialist and in many cases, it is a family business. IT is not used optimally in such cases and also has a bad impact on the business and competitive advantage. This problem is observed in many analyzes, which show that differences in the effectiveness of CRM systems are associated with differences in sales processes [7] or enterprises have a low level of CRM strategy and has an impact on sales and marketing strategy with an influence on customer loyalty [18]. This paper continues its work to show that the optimal choice of CRM system is not so difficult if it is based on appropriate metrics for evaluating the selected CRM system according to business preferences and options with sufficient sensitivity to customers and international relationships in a global society. The methodological solution is based on:

(1) Literature review for international relationships (Chapter 1) and CRM systems (Chapter 2).

(2) The existing problem was identified on the basis of the controversy between IT capabilities and IT implementation in small business. It is a responsible selection of CRM for IT implementation according to the needs, skills, and possibilities in small business and customer expectations and opportunities in the field of competition.

(3) The specification of appropriate metrics for CRM evaluation has been implemented to identify processes to be improved. The entered metrics (criteria) were compared with the Fuller's triangle in order to find their weights.

(4) For selected CRM systems, the necessary data were collected to demonstrate the expected benefits of their implementation to improve low-interest (weighted) metrics.

Finding the right metrics is a crucial step in demonstrating the most important benefits of CRM systems, and also to minimize weakness. There are many of the best lists, such as the best CRM software of the year [22], or use filters to select CRM according to criteria [23]. But such a search is unclear, because many criteria are mentioned, and it is not easy to compare the various options. For this paper, it is about supporting international relationships through CRM. It is primarily about communication, understanding and respect for customers of different cultures. It is necessary to stay in touch, understand local preferences, use optimal information technology, and support customer loyalty. From the CRM point of view, these are: 
- Segmentation helps maintain contact with relevant customers.

- Support for automation or at least templates for better CRM processes (marketing, sales, or default contact management).

- Free access to information technology helps to ensure that such communication may be free of financial barriers based on mobile access and cloud.

- Sharing positive stories and brand information is important to keep thinking about customers to increase their loyalty through social media integration.

These seven metrics were selected for analysis (automation, cloud, free access, mobile access, segmentation, social media integration, and templates) by the Fuller's triangle [24, 25] from a small business perspective. See Table 1.

Table 1. Evaluation of specified metrics (criteria) by the Fuller's triangle.

\begin{tabular}{|c|c|c|c|c|c|c|c|}
\hline $\begin{array}{c}\text { Specified } \\
\text { metrics }\end{array}$ & automation & cloud & $\begin{array}{c}\text { free } \\
\text { access }\end{array}$ & $\begin{array}{c}\text { mobile } \\
\text { access }\end{array}$ & segmentation & $\begin{array}{c}\text { social } \\
\text { media } \\
\text { integration }\end{array}$ & templates \\
\hline & $\mathbf{1}$ & 1 & 1 & $\mathbf{1}$ & 1 & 1 \\
\hline & 2 & $\mathbf{3}$ & $\mathbf{4}$ & 5 & $\mathbf{6}$ & $\mathbf{7}$ \\
\hline & & 2 & 2 & 2 & 2 & 2 \\
\hline & & $\mathbf{3}$ & $\mathbf{4}$ & $\mathbf{5}$ & $\mathbf{6}$ & $\mathbf{7}$ \\
\hline & & & $\mathbf{3}$ & $\mathbf{3}$ & $\mathbf{3}$ & $\mathbf{3}$ \\
\hline & & & 4 & 5 & 6 & 7 \\
\hline & & & & & & & \\
\hline
\end{tabular}

Fuller's method defines the total volume of comparisons (TVC) such as number based on the number of metrics analysed (NMA), and this relation is:

$$
T V C=\frac{N M A *(N M A-1)}{2}
$$

This analysis works with 7 items, where $N M A=7$ and $T V C=21$. The Fuller's triangle method uses comparison of metrics. Metrics of great importance are highlighted (bold and gray). The preferences $\left(P_{i}\right.$ for $\left.i=1, \ldots, 7\right)$ are calculated by summing the number of highlights comparisons for each metrics. The weights $v_{i}$ for $i=1, \ldots, 7$ are calculated with the relation using preferences $\left(P_{i}\right)$ and total comparison volume $(T V C)$ : 


$$
v_{i}=P_{i} / T V C
$$

Based on these results from a CRM perspective, the metrics are sorted from free access (weight 0.286), mobile access and templates (weight 0.190), segmentation (weight 0.143), automation and social media integration (weight 0.095), and cloud (weight 0.000).

\section{Results and Discussion}

This assessment reflects the pragmatic reality of this small business, and request zero-cost CRM implementation to support international relationships. Great preferences are for free and mobile access, because the future CRM implementation must be based on minimal or zero costs and mobile access is used, so there are no new costs. Another great interest is in templates. The reason is that templates are well known for this business and IT user remember them very well. Metrics that are not used are low, and there are doubts about their successful implementation in the business. It is about segmentation, automation, social media integration. At the bottom of the list is the interest in the cloud solution, and this metric has zero preferences.

The discussion is about a suitable vision for the future development of such business in a global society. In terms of CRM implementation, there are simpler systems or tools to support customer communication, and the costs are minimal or non-existent. Many of them offer free and mobile access (and of course the cloud too). In this example, the weakness is understanding the importance of automating and integrating social media. In particular, automation has a strong power to promote optimal segmentation, which is also of little interest in developing better international relationship with customers. For this small business, it is not about robust CRM systems such as Salesforce, Hubspot, or SugarCRM. They offer a comprehensive menu and are more difficult to manage. The solution consists of using user-friendly and small CRM solutions, such as Amo CRM, eWay-CRM, or Zoho CRM:

- Amo CRM offers a wide range of options to support customer communication, and optimal care is also provided for automated procedures. Social network integration is not as detailed and also lack various templates to guide IT user at work. For the future, it is one of the top CRM systems.

- $\quad$ eWay CRM has very well implemented automatic procedures and templates. There is also room for various customer communication. Social media is not so widely implemented. For the future, it is one of the most affordable CRM systems.

- Zoho CRM is a system with very good support for automated procedures, and good integration of social networks. Working with key performance indicators is optimal and IT users choose from various cannels for customer communication. For the future, it is one of the most popular CRM systems.

There are simpler solutions on the CRM market, such as IZIO or Agile CRM. The advantage is communication with a clear menu and appropriate support, such as video, so that one knows about the system as soon as possible, but the automation and social media integration are not so complex.

\section{Conclusion}

International relationships reflect many relationships between people in a global society. Their development is supported by modern information technologies to make purchases through websites and e-shopping. It is not about place and time in a given locality, it is about understanding international relationships and knowledge of different preferences, cultures, possibilities, and traditions. To influence growing sales, international relationships have a 
strong power to promote long-term customer contacts and loyalty. It is natural that CRM systems have an irreplaceable impact on CRM in enterprises, and they are interested in marketing automation, sales force automation, knowledge management, channel management, and call centres. This is very sensitive issue for small business because they lack IT specialist and other resources. The optimal choice of CRM system according to preferences from the point of view of a small business is solved by the Fuller's triangle. The necessary data was collected and specific metrics such as automation, cloud, free access, mobile access, segmentation, social media integration, and templates were established. According to the calculated weights, these metrics are sorted from the largest weight (free access) to the smallest (cloud). In the middle are mobile access and templates. There is a lack of interest in segmentation and automation with the social media integration. The reason is the hard pressure for zero costs for future CRM implementation and low CRM knowledge. For future support of international relationships, it is recommended to focus on simpler solutions, such as e-Way CRM or Zoho CRM, which are the most affordable and the most popular, but also offer good support for automated procedures, templates, or integration of social network. The reason is that these issues are a weakness in this small business and need to be improved.

The acknowledgements: This paper was supported by the project no. SGS/19/2019, "Application of Customer Relationship Management Systems in Small and Medium-sized Enterprises" accepted in 2019.

\section{References}

1. Hallikainen, H., Savimaki, E., Laukkanen, T. (2020). Fostering B2B sales with customer big data analytics. Industrial Marketing Management, 86.

2. Shahbaz, M., Gao, C., Zhai, L., Shahzad, F., Abbas, A., Zahid, R. (2020). Investigating the Impact of Big Data Analytics on Perceived Sales Performance: The Mediating Role of Customer Relationship Management Capabilities. Complexity, 2020, 5186870.

3. Nithya, N., Kiruthika, R. (2020). Impact of Business Intelligence Adoption on performance of banks: a conceptual framework. Journal of Ambient Intelligence and Humanized Computing, forthcoming article.

4. Serova, E. (2019). Artificial Intelligence for Analysis of Collaborative Consumer Networks Management. In P. Griffiths \& M. N. Kabir (Eds.), Proceedings of the European Conference on the Impact of Artificial Intelligence and Robotics ECIAIR 2019 (pp. 304-311). Oxford, England: ECIAIR.

5. Atanasova, V. (2018). Advantages and Deficiencies in the Use of CRM in Hotels. Scientific Papers-Series Management Economic Engineering in Agriculture and Rural Development, 18(4), 47-51.

6. Cosgrave, D., O'Dwyer, M. (2020). Ethical standards and perceptions of CRM among millennial consumers. International Marketing Review, forthcoming article.

7. Rodriguez, M., Peterson, R. M., Krishnan, V. (2018). Impact of CRM technology on sales process behaviors: empirical results from US, Europe, and Asia. Journal of Business-To-Business Marketing, 25(1), 1-10.

8. Taylor, M. (2020, September 17). 8 CRM Statistics You Need to Know for 2020. Retrieved from: https://www.superoffice.com/blog/crm-software-statistics/

9. Nazari-Shirkouhi, S., Keramati, A., Rezaie, K. (2015). Investigating the Effects of Customer Relationship Management and Supplier Relationship Management on New Product Development. Tehnicki Vjesnik-Technical Gazette, 22(1), 191-200. 
10. Santouridis, I., E. Tsachtani (2015). Investigating the Impact of CRM Resources on CRM Processes: a Customer Life-Cycle Based Approach in the Case of a Greek Bank. Procedia Economics and Finance, 19, 304-313.

11. Totah, Z. (2020, April 29). CRM Requirements Checklist and Evaluation. Retrieved from: https://www.selecthub.com/customer-relationship-management/crm-require ments-checklist-and-downloadable-template/

12. Islamgaleyev, A., Petrova, M., Kurenkeyeva, G., Shalbayeva, S., Kadirbergenova, A. (2020). Increasing Customer Focus in Metal Trading. Entrepreneurship and Sustainability Issues, 8(1), 604-617.

13. Harrigan, P., Miles, M. P., Fang, Y. L., Roy, S. K. (2020). The role of social media in the engagement and information processes of social CRM. International Journal of Information Management, 54, 102151.

14. Eng, T. Y., Ozdemir, S., Gupta, S., Kanungo, R. P. (2020). International social entrepreneurship and social value creation in cause-related marketing through personal relationships and accountability. International Marketing Review, forthcoming article.

15. Bonney, L., Plouffe, C. R., Hochstein, B., Beeler, L. L. (2020). Examining salesperson versus sales manager evaluation of customer opportunities: A psychological momentum perspective on optimism, confidence, and overconfidence. Industrial Marketing Management, 88, 339-351.

16. Libai, B., Bart, Y., Gensler, S., Hofacker, C. F., Kaplan, A., Kotterheinrich, K., Kroll, E. B. (2020). Brave New World? On AI and the Management of Customer Relationships. Journal of Interactive Marketing, 51, 44-56.

17. Stormi, K., Lindholm, A., Laine, T., Korhonen, T. (2020). RFM customer analysis for product-oriented services and service business development: an interventionist case study of two machinery manufacturers. Journal of Management \& Governance, 24(3), 623-653.

18. Lam, H. Y., Tsang, Y. P., Wu, C. H., Tang, V. (2020). Data analytics and the P2P cloud: an integrated model for strategy formulation based on customer behaviour. Peer-To-Peer Networking and Applications, forthcoming article.

19. Zhang, Z., Dai, Y. (2020). Combination classification method for customer relationship management. Asia Pacific Journal of Marketing and Logistics, 32(5), 1004-1022.

20. Nguyen, B., Chen, J., Foroudi, P., Yu, X., Chen, CHS. Yen, D. A. (2020). Impact of CRM strategy on relationship commitment and new product development: mediating effects of learning from failure. Journal of Strategic Marketing, forthcoming article.

21. Castagna, F., Centobelli, P., Cerchione, R., Esposito, E., Oropallo, E., Passaro, R. (2020). Customer Knowledge Management in SMEs Facing Digital Transformation. Sustainability, 12(9), 3899.

22. McLaughlin, M., Marvin, R., Sevilla, G. (2020, April 10). The Best CRM Software for 2020. Retrieved from: https://www.pcmag.com/picks/the-best-crm-software

23. Capterra - CRM Software. (2020, September 10). Retrieved from: https://www.capterra.com/customer-relationship-management-software/

24. Agarski, B., Hadzistevic, M., Budak, I., Moraca, S., Vukelic, D. (2019). Comparison of approaches to weighting of multiple criteria for selecting equipment to optimize performance and safety. International Journal of Occupational Safety and Ergonomics, 25(2), 228-240.

25. Carlsson, C., Fuller, R. (1996). Fuzzy multiple criteria decision making: recent developments. Fuzzy Sets Syst, 78, 139-153. 